\title{
Comparison of Safety and Efficacy of Al- Hijama (Cupping) and Conventional Medical Therapy for Sinusitis (I)
}

\author{
Eman A. Ghazy ${ }^{1,3}$, MBBCh, Saad M. Al Muhayawi², MBBCh, FRCSC, \\ Samiha A. Mourad ${ }^{3}$, MD, Rawan A. Alahdal ${ }^{4}$, Pharm D \\ 'University Medical Services Center, King Abdulaziz University, Jeddah, Saudi Arabia \\ ${ }^{2}$ Department of Otolaryngology \& Head \& Neck Surgery, Faculty of Medicine, King Abdulaziz University, \\ Jeddah, Saudi Arabia \\ ${ }^{3}$ Hijama Clinic; Yousef Abdullatif Jameel Chair of Prophetic Medicine Application, Faculty of Medicine, King \\ Abdulaziz University, Jeddah, Saudi Arabia \\ ${ }^{4}$ Faculty of Pharmacy, King Abdulaziz University, Jeddah, Saudi Arabia
}

\section{Correspondence \\ Dr. Eman A. Ghazy \\ University Medical Services Center \\ King Abdulaziz University \\ P.O. Box 80205 \\ Jeddah, Saudi Arabia \\ e.M: dr.eman.g@hotmail.com \\ Submission: 11 Sept. 2018 \\ Accepted: $\quad 05$ Dec. 2018}

\section{Citation}

Ghazy EA, Al Muhayawi SM, Mourad SA, Alahdal

RA. Comparison of safety and efficacy of Al-

Hijama (cupping) and conventional medical therapy for sinusitis (I). JKAU Med Sci 2018; 25

(2): 11-26. DOI: 10.4197/Med. 25.2.2

Copyright: $\odot$ The Author(s), YEAR. Publisher. The Journal of King Abdualziz University - Medical Sciences is an Official Publication of "King Abdulaziz University". It is an open-access article distributed under the terms of the Creative Commons Attribution Non-Commercial License, which permit umrestricted non-commercial use distribution, and reproduction in any me

\begin{abstract}
The study aims to evaluate safety and efficacy of Al-Hijama (wetcupping) either as an adjuvant or an alternative to conventional medication therapy among adult patients with sinusitis. A randomized controlled clinical trial was conducted at Prophetic Medicine Research Cupping Clinic, King Abdulaziz University Hospital, Jeddah Saudi Arabia. The study used a simple randomization technique. Sixty (60) patients of chronic or recurrent acute sinusitis were divided equally into 3 groups. The first group had Hijama with drug therapy, second had Hijama plus salt nasal solution and mild analgesic if needed, and the third was treated with ordinary medicine regularly. The effect of AlHijama on sinusitis symptoms, use of medications, were studied. The results showed that both alternative and adjuvant Al-Hijama therapies were superior to conventional therapy with regard to the reduction of symptom frequency, severity, duration and use of medication. AlHijama therapy was effective, simple, affordable, acceptable, and safe when used correctly. It is expected that all patients with sinusitis would benefit from Al-Hijama.
\end{abstract}

\section{Keywords}

Sinusitis; Al-Hijama; Cupping; Prophetic medicine

\section{Introduction}

$S$ inusitis (rhinosinusitis), an inflammation of mucous membrane that lines the paranasal sinuses (i.e., airfilled spaces in the skull and facial bones), is one of the most common health problems worldwide that affects 1 in 7 individuals in United States annually. Sinusitis may be acute (lasting for $\leq 4$ weeks), chronic (lasting for 4-12 weeks or longer), or recurrent (attacks return several times within 1 year). Quality of life scores for chronic sinusitis is also related with serious illnesses ${ }^{[1,2]}$. Sinusitis may be caused by a viral (main cause) or bacterial infection, allergies, air pollution, or dysfunctional nasal morphology. Common sinusitis symptoms include a thick nasal mucus, plugged nasal passages, and facial pain; although, other symptoms including fever, headache, poor sense of smell, sore throat, and cough (worsens at night) have been reported ${ }^{[3]}$. 
Current recommendations indicated symptomatic or adjunctive therapies as initial treatment for acute sinusitis ${ }^{[4]}$. Most sinusitis cases are viral and will resolve without antibiotics within 10 days ${ }^{[5]}$. However, antibiotics are often administered unnecessarily for such cases. In addition to being ineffective for viral infection, recurrent antibiotics usage weakens the immune system, causes antibiotic resistance, and can result in a chronic condition.

For chronic sinusitis or symptoms that persist or worsen over 7-10 days, amoxicillin is recommended as the initial treatment of choice for bacterial sinusitis, and corticosteroids may also be helpful. However, surgery may be indicated for resistant chronic or recurring sinusitis ${ }^{[6,7]}$. Other complementary treatment choices have been reported, including apitherapy and aqua-puncture ${ }^{[8,9]}$. If not treated timely and adequately, sinusitis can lead to serious complications including inflammation or abscesses of the skull bones, infections of the eye, abscesses under the periosteum or of the orbital, thrombosis of the cavernous sinus, loss of smell, meningitis, and/or epidural, subdural, or other brain abscesses $^{[10]}$.

Arabic word Al-Hijama means "cupping". Prophet Mohammad (Peace be upon Him) says, "If any of your treatment modalities are beneficial, the benefit will be from the blade puncture in cupping therapy, a dose of honey, and cauterization, but Ido not like cauterization"[11].

Currently, cupping therapy is practiced in many countries worldwide ${ }^{[12]}$. Two main types of cupping therapy are used, including dry and wet ${ }^{[13,14]}$. The wet cupping (Al-Hijama, as in Prophetic medicine) comprises a three-step technique involving suction, scarification, and suction. Taibah theory states that AlHijama clears causative pathological substances (CPS) from the blood and interstitial fluids ${ }^{[15,16]}$. Previous studies have found that wet-cupping could successfully treat patients with headache in a primary care setting, and Al-Hijama yields better results when performed at pain sites ${ }^{[17]}$. Al-Hijama was reported to increase the pharmacological effects of drugs, improve the immune system and remove pathogenic, allergenic, and inflammatory factors from the blood, lymph, and interstitial fluid. Additionally, previous studies have not reported any complications, caused by correctly performed Al-Hijama ${ }^{[12,15]}$.

Cupping is recommended as a complementary treatment modality for many chronic medical conditions. The study aims to compare the efficacy and safety of Al-Hijama as an adjuvant or alternative to pharmacological therapy versus conventional medical treatment for the symptoms and the use of drugs for sinusitis.

\section{Methods}

A randomized controlled clinical trial was conducted at Prophetic Medicine Research Cupping Clinic, King Abdulaziz University (KAU), Jeddah, Saudi Arabia from January 2016 to March 2017. The trial is registered with the National Committee of Biological \& Medical Ethics under number HA-02-J-008. The referred patients were divided into three study groups according to the mode of treatment; after which, the author selected 20 patients from each group using a simple randomization technique (file number selection). Al-Hijama is clear for both patient and therapist, so trial was not blinded. All adult patients (male or female) diagnosed as chronic or recurrent acute sinusitis, aged between 15 and 65 years, stable cases, were not treated with Al- Hijama for sinusitis before. Sixty patients were divided equally into three groups of 20 patients:

- Group I received Al-Hijama as an adjuvant to the main sinusitis drug therapy.

- Group II received Al-Hijama as main treatment with a salt solution five times per day and mild analgesic as (paracetamol) if needed.

- Group III received conventional sinusitis medication regularly for one week. These treatments were: antibiotics as amoxicillin 500 mg three times a day (TDS) antihistamine once daily, nasal spray containing corticosteroid TDS as flixonase or nasonex.

All participants were required to complete the questionnaire regarding symptoms recurrence, duration, presence, and severity. Drug therapies (if used), complimentary treatment use, degree of improvement after medical or Al-Hijama treatment, and the expectation of improvement from Al-Hijama, were graded on a 3-point Likert scale using clear, simple, and closed-ended phrases ${ }^{[18]}$.

Patients were examined during initial outpatient visits to University Medical Services Center General Clinic at KAU or the Ear, Nose, and Throat (ENT) clinic at KAU Hospital (KAUH). Patients who fulfilled the inclusion criteria were referred to Prophetic Medicine 
Clinic, where they completed a questionnaire before cupping and provided written consent. During a onemonth period, patients made three visits to the clinic at two-week intervals. Each session included cupping on 8 points, 6 points wet cupping (above and medial to both eyebrows over sinuses, over $7^{\text {th }}$ cervical vertebra, $3 \mathrm{~cm}$ below it, on both sides of the neck behind and below both ears) and 2 points dry cupping (over sinuses on both sides of the nose above the alae nasal). According to the steps explained in the Taibah theory, shallow scarification incisions (approximately 1-2 mm long and $<0.2 \mathrm{~mm}$ deep) were made. The patients were re-evaluated after three months, at which time they again completed questionnaires. The data was analyzed using the IBM SPSS Statistics for Windows, Version 20 (IBM Corp., Armonk, NY USA). Qualitative data are expressed as frequencies and percentages.

\section{Results}

Seventy-seven patients were referred; however, only 60 patients completed the questionnaire, representing $78 \%$ of response rate. $86 \%$ of the sample was consisted of Saudi nationals, $60 \%$ patients were aged between $36-50$ years. $91.6 \%$ of the sample were females, $83.3 \%$ patients suffered from allergies, and $80 \%$ patients suffered from sinusitis for more than 3 years. Table 1 presents a comparison of post-treatment symptoms in the three studied groups. Patients in Groups I and II exhibited statistically significant improvements in the frequency, duration, severity and number of symptoms when compared with group III.

Table 2 presents a comparison of sinusitis symptoms before and after adding Al-Hijama treatment. Al-Hijama had significant positive effects on the frequency, duration, severity, and number of symptoms in both Al-Hijama-treated groups. A p-value $<0.05$ is considered significant; a $p$-value $<0.001$ is highly significant (chi-squared test).

Table 3 presents a comparison of using medication after treatment in the three studied groups. The groups exhibited highly statistically significant differences, with the use of drug therapy increasing in the group treated with medication only. Table 4 demonstrates a comparison of using medications before and after AlHijama treatment. Notably, medication use decreased drastically in both Al-Hijama-treated groups. A p-value $<0.05$ was considered significant; a $p$-value $<0.001$ was highly significant (chi-squared test). None of the participants complained of or reported any adverse events after the Al-Hijama treatment.

\section{Discussion}

There were no potential sources of bias or limitations during the trial. According to the results, Al-Hijama improved sinusitis symptoms and reduced the use of medication therapy. As shown in Table 1, patients in both Al-Hijama groups exhibited significant improvements in the frequency, duration, severity, and types of symptoms when compared to patients treated with conventional medication alone. Furthermore, Table 2 revealed significant differences in patients' responses regarding the effects of Al-Hijama on the rate of sinusitis symptom recurrence. For instance, the rate of multiple recurrences per month was decreased from $85 \%$ before treatment to $0 \%$ after treatment in Group I and from 75\% to 0\%, respectively, in Group II; but remained at $55 \%$ in Group III. Furthermore, the rate of a single recurrence per three months was increased from $5 \%$ to $30 \%$ in Group I and from $5 \%$ to $30 \%$ in Group II, whereas the rate remained at 15\% in Group III.

Additionally, patients reported significantly different symptom durations with regard to Al-Hijama usage. For example, the proportion of patients, who reported continuous symptoms, decreased from 30\% to $0 \%$ in Group I and from 30\% to $10 \%$ in Group II, whereas the proportion remained at $10 \%$ in Group III. The proportion of patients who reported that their symptoms only lasted for hours increased from 5\% to $60 \%$ in Group I and from $5 \%$ to $35 \%$ in Group II but remained at $10 \%$ in Group III. In other words, the patients' views regarding the level of improvement in symptom quality and severity differed significantly and supported the use of Al-Hijama.

The study has compared sinusitis symptoms before and after treatment in two Al-Hijama treated groups and observed no difference in outcomes. It has been evaluated that Al-Hijama had a significant positive effect on symptom frequency, duration, type, and severity and that the two treatment modalities (pharmacological vs. nasal salt solution) did not yield different outcomes. However, this could indicate the misuse of medications by patients or physicians.

Tables 3 and 4 addressed the usage of treatments for sinusitis and related improvements. As shown in Table 3, a comparison of three studied groups showed 


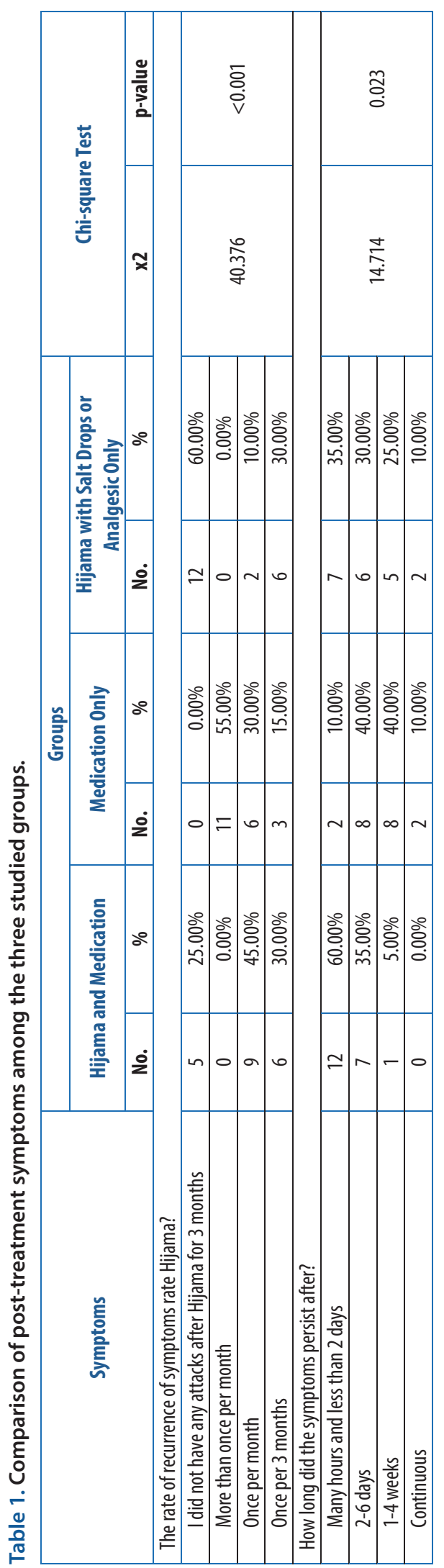


Comparison of Safety and Efficacy of Al-Hijama (Cupping) and Conventional Medical Therapy for Sinusitis (I) E.A. Ghazy et al.

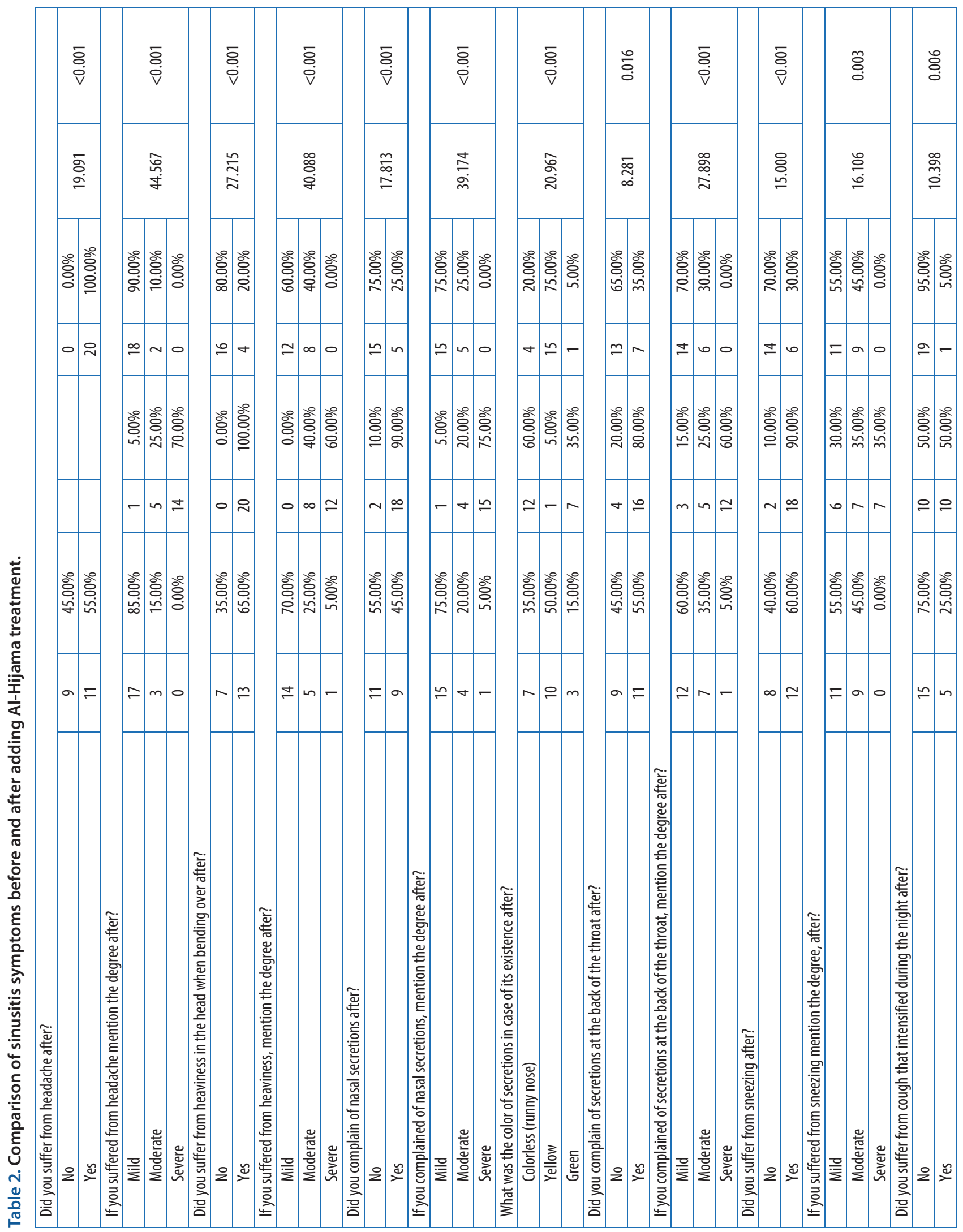


Comparison of Safety and Efficacy of Al-Hijama (Cupping) and Conventional Medical Therapy for Sinusitis (I) E.A. Ghazy et al.

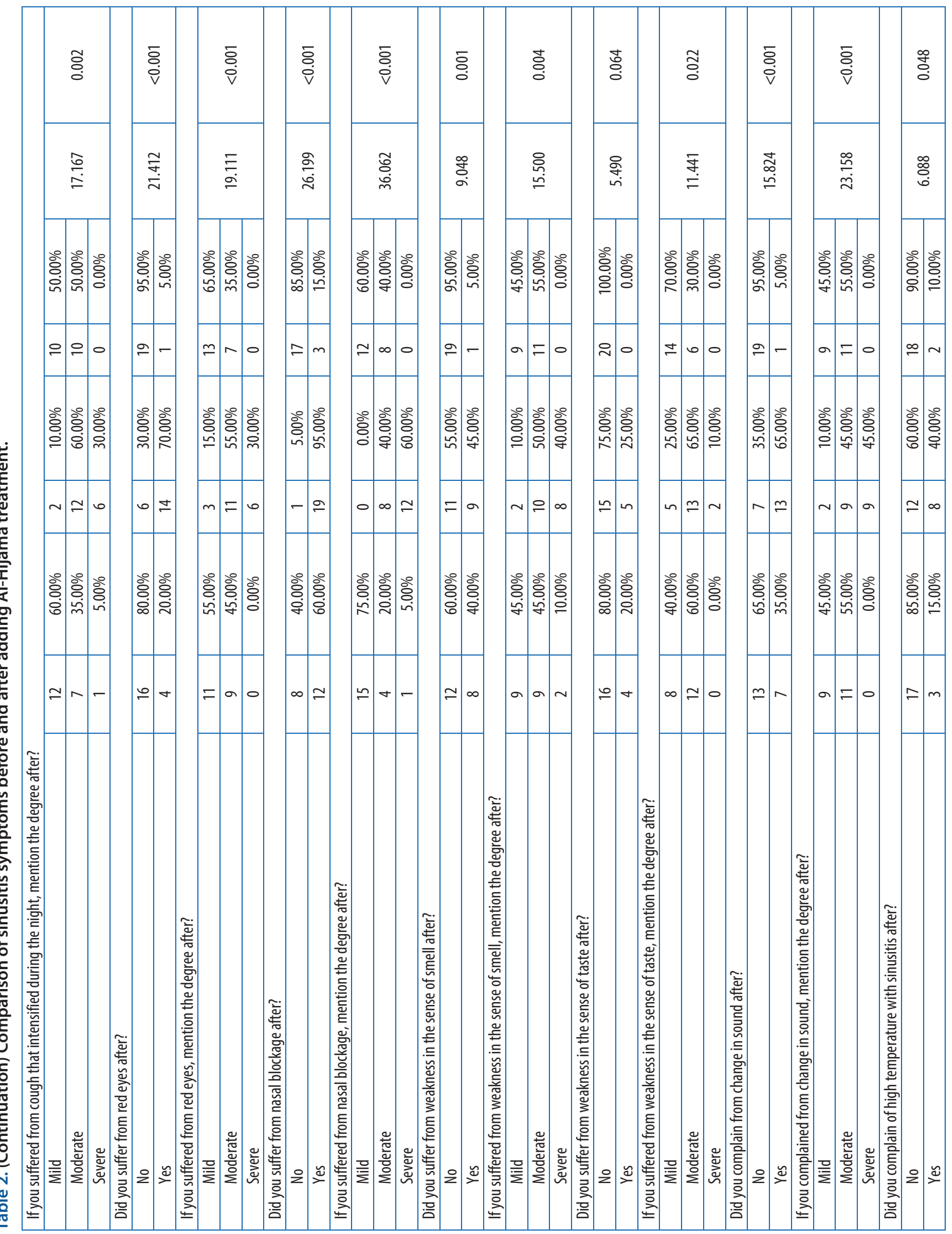


Comparison of Safety and Efficacy of Al-Hijama (Cupping) and Conventional Medical Therapy for Sinusitis (I) E.A. Ghazy et al.

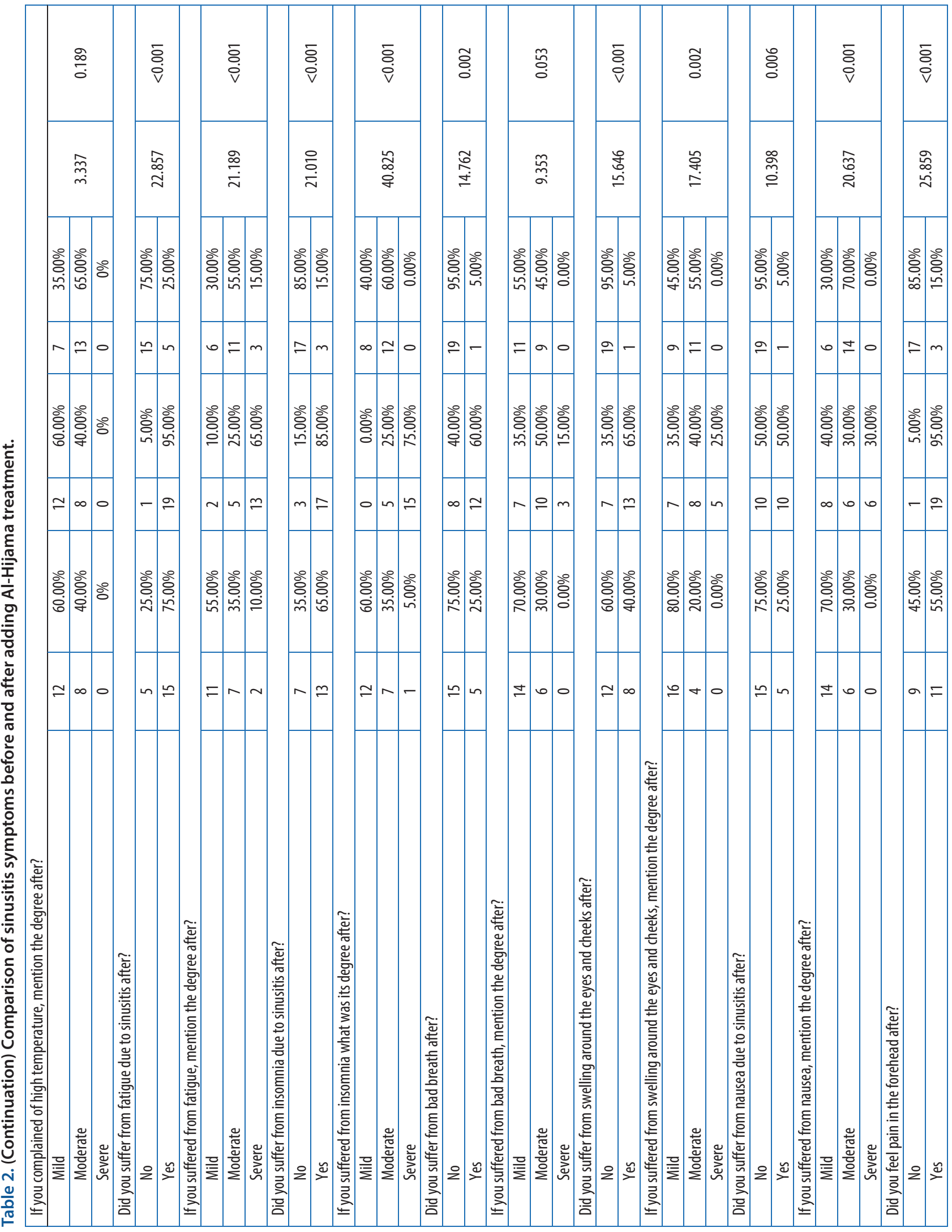



E.A. Ghazy et al.

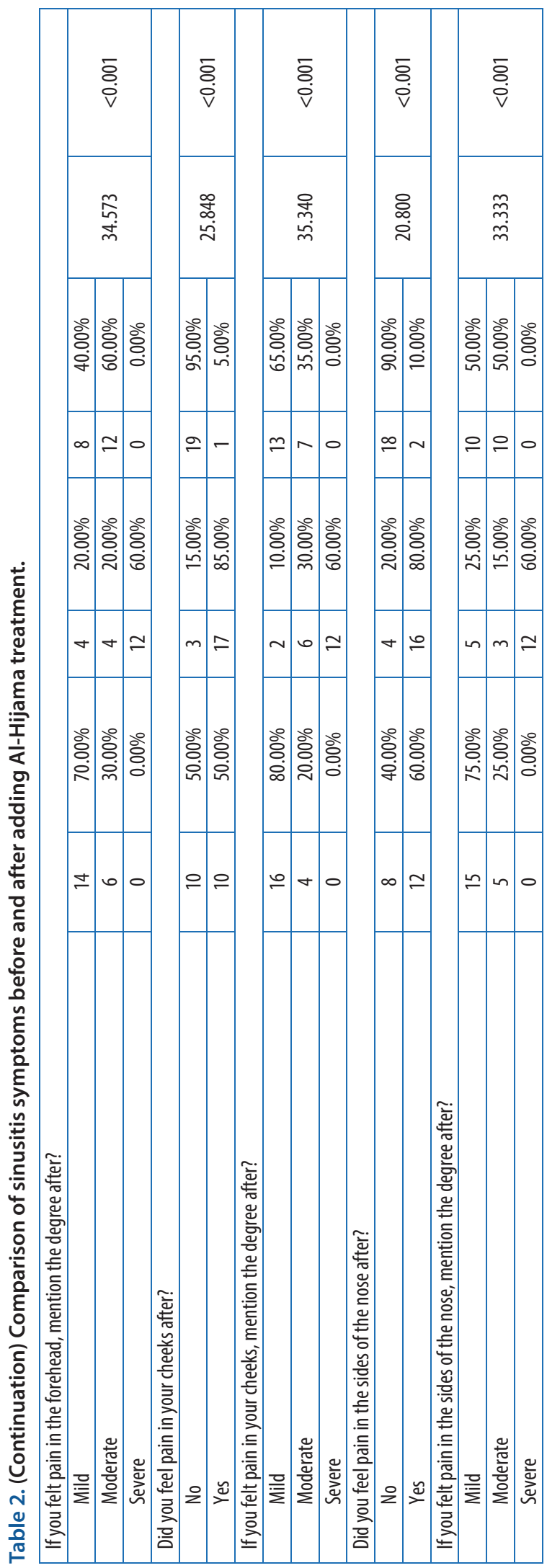


Comparison of Safety and Efficacy of Al-Hijama (Cupping) and Conventional Medical Therapy for Sinusitis (I) E.A. Ghazy et al.

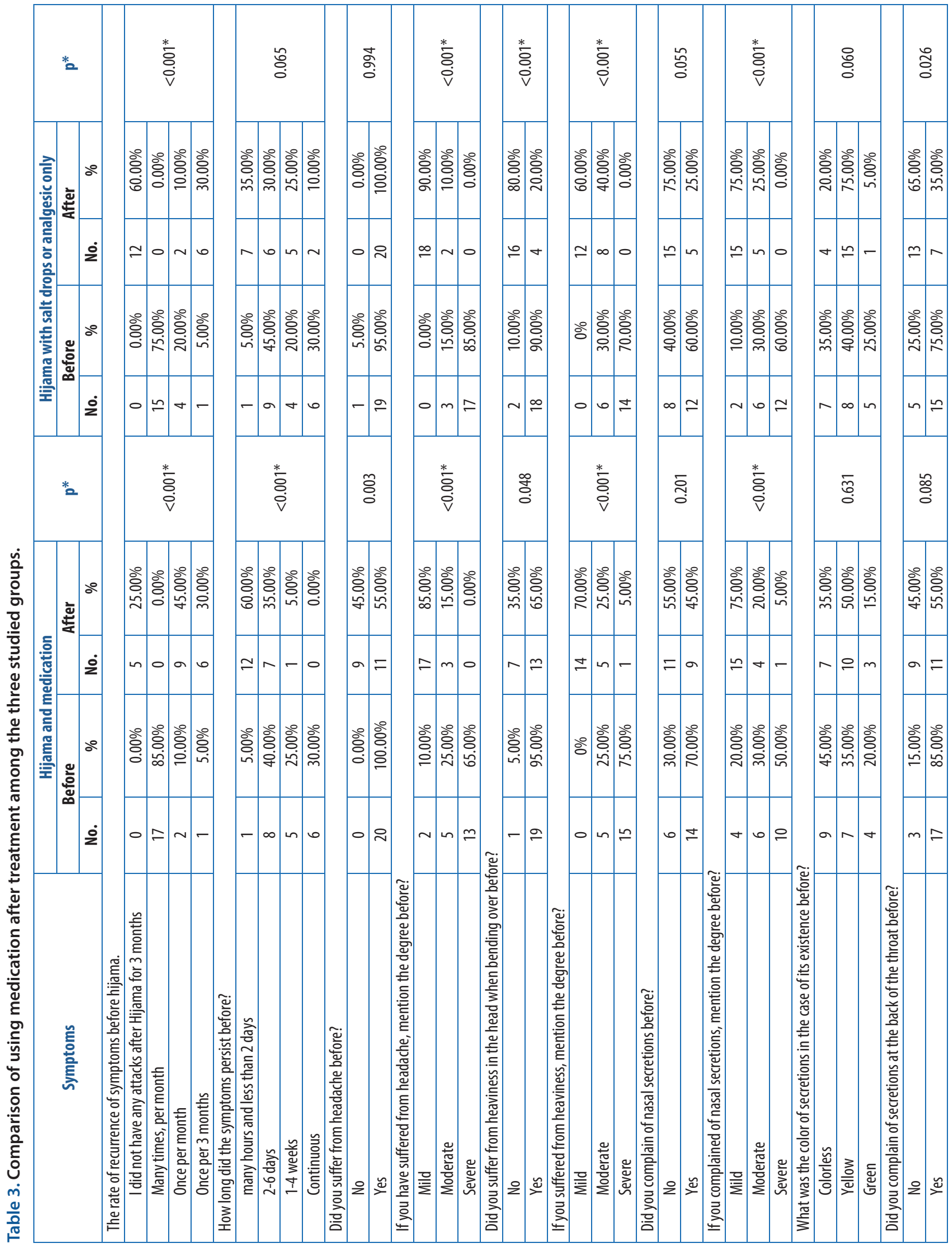


Comparison of Safety and Efficacy of Al-Hijama (Cupping) and Conventional Medical Therapy for Sinusitis (I) E.A. Ghazy et al.

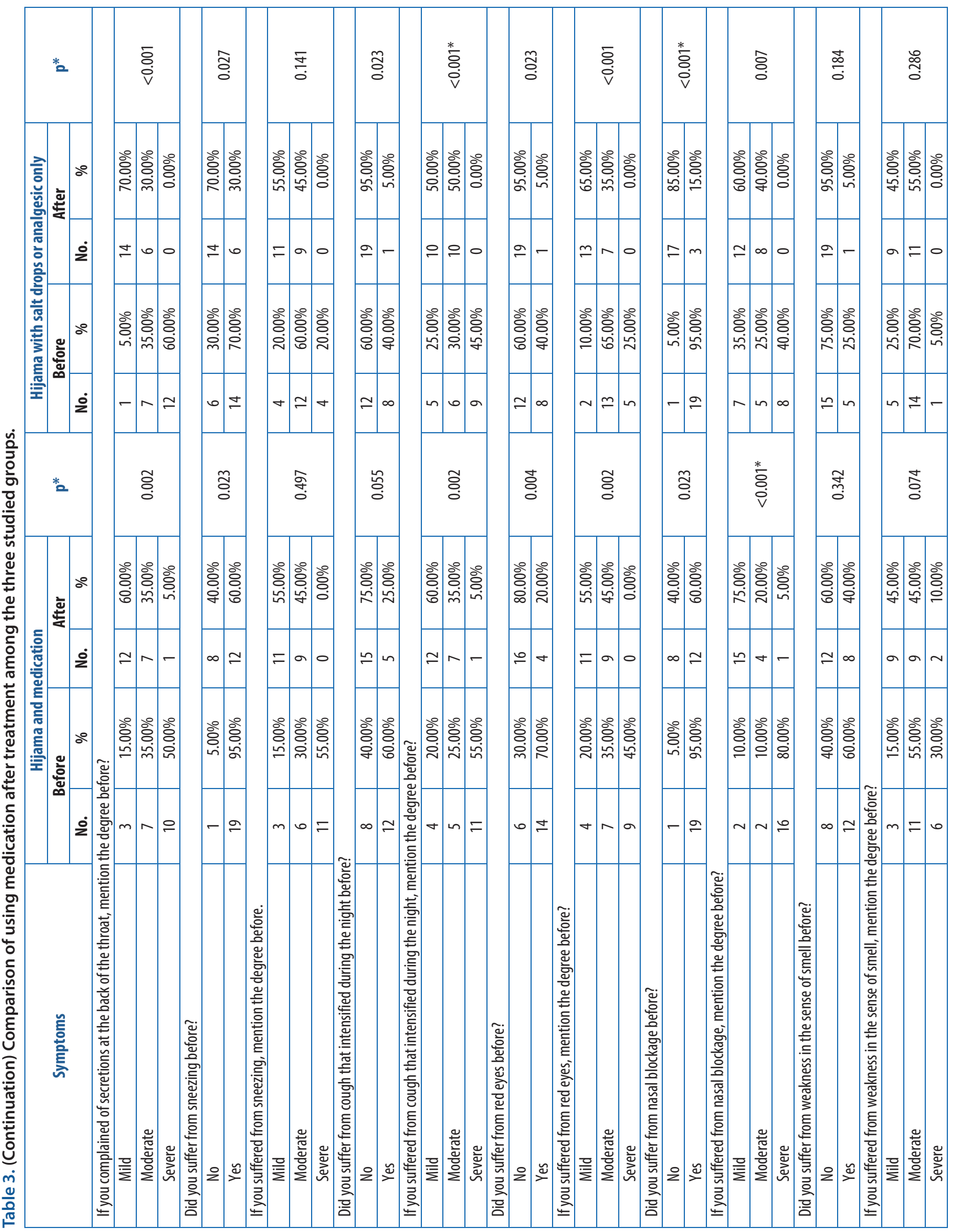


Comparison of Safety and Efficacy of Al-Hijama (Cupping) and Conventional Medical Therapy for Sinusitis (I) E.A. Ghazy et al.

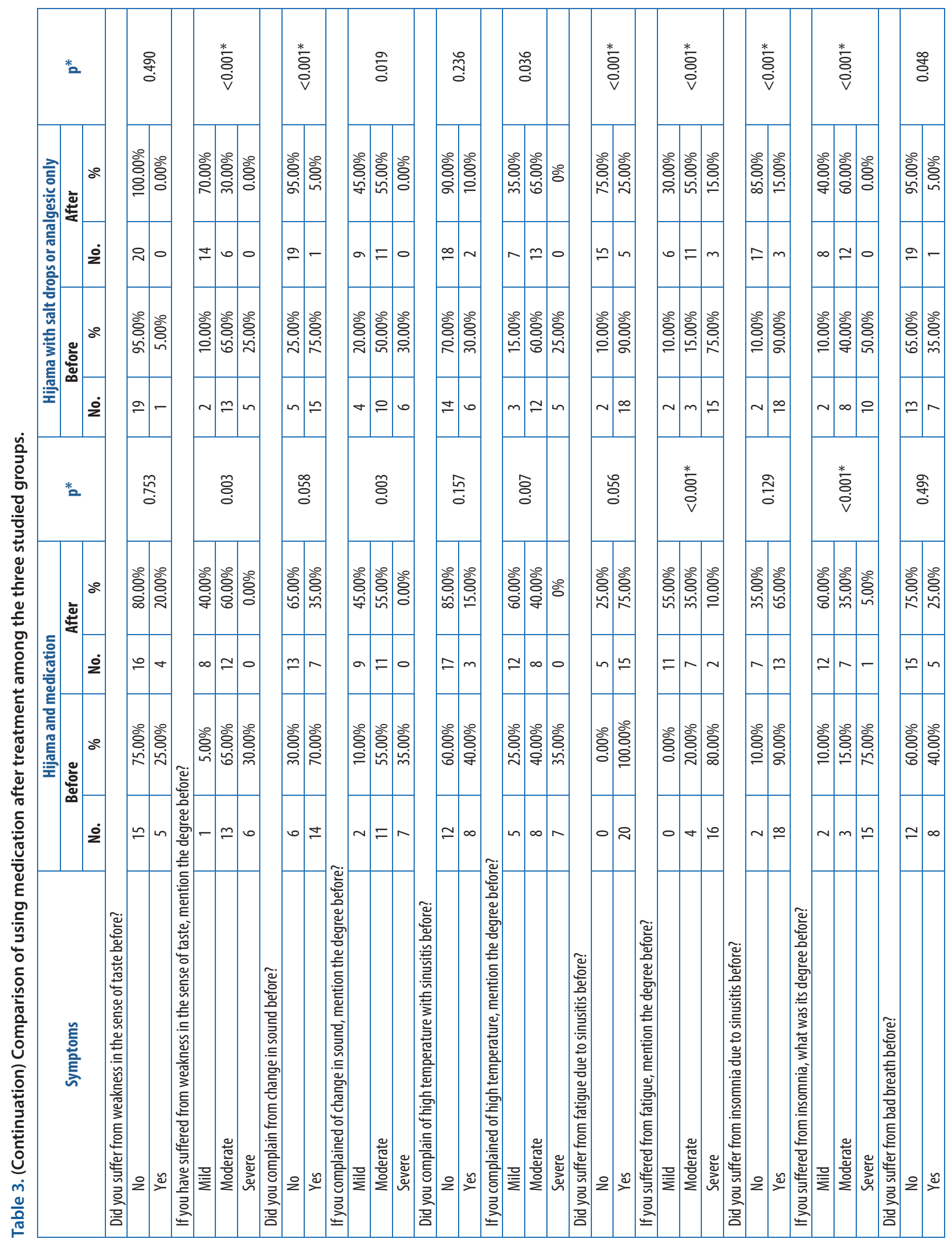




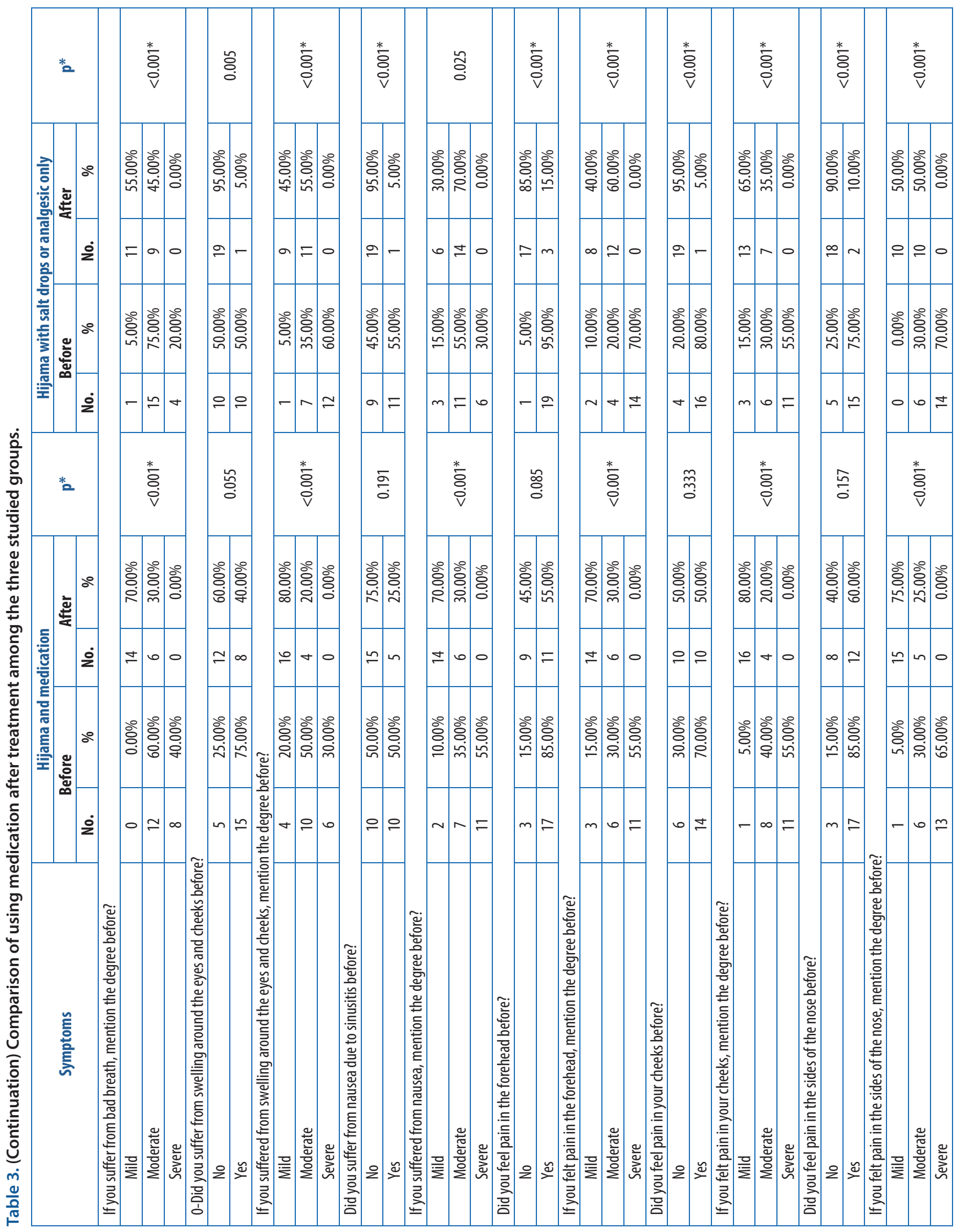




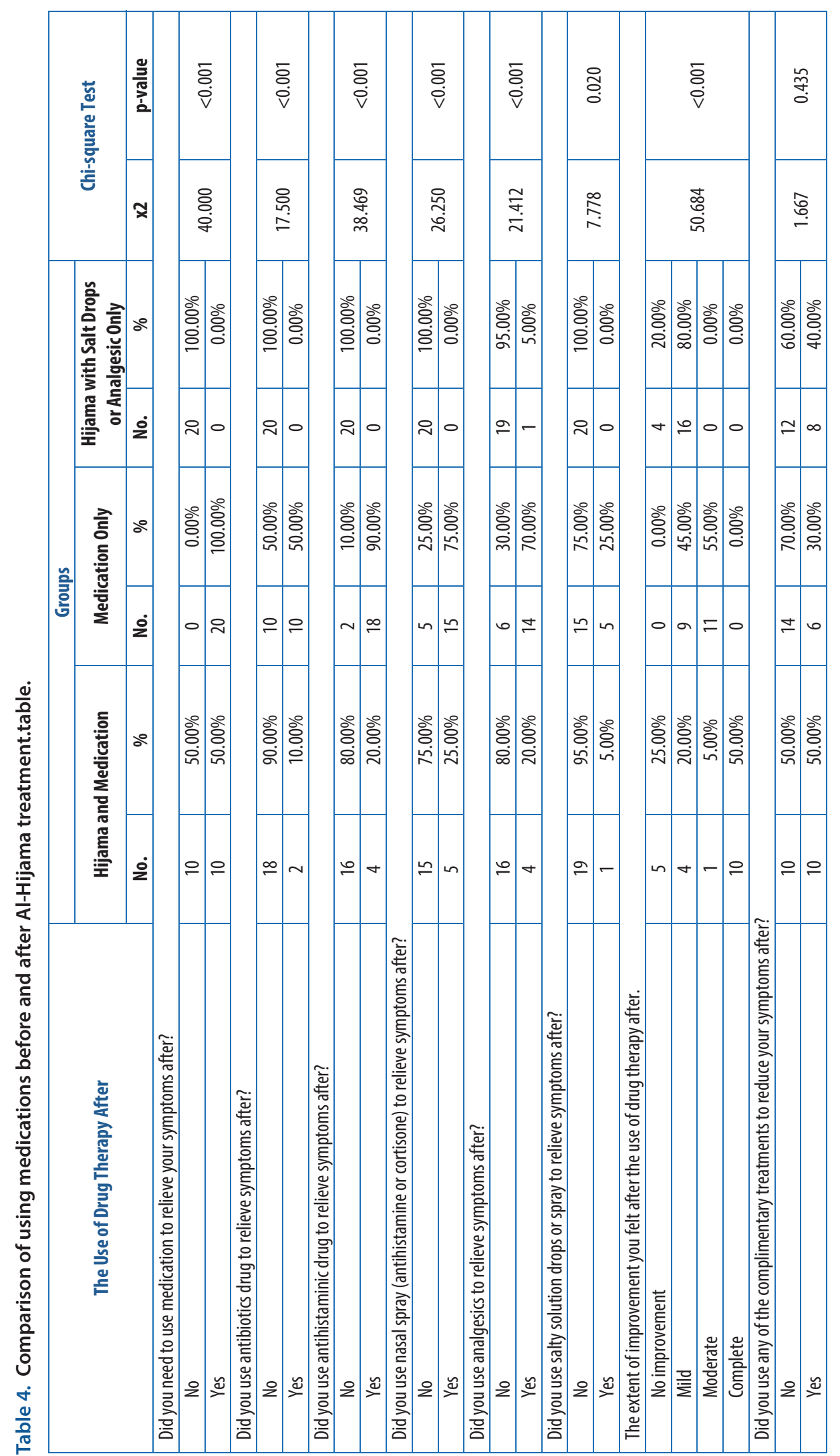


that two groups, treated with Al-Hijama, decreased their use of medication as compared to those treated with medication only. Furthermore, Table 4 shows that both groups treated with Al-Hijama exhibited dramatic decreases in using medication from before to after treatment; specifically, $50 \%$ no longer required medicine, the rate of antibiotics use decreased from $60 \%$ to $10 \%$, the rate of antihistamine use decreased from $80 \%$ to $20 \%$, the rate of antihistamine- or cortisonecontaining nasal spray use decreased from $80 \%$ to $25 \%$, the rate of analgesic use decreased from $85 \%$ to $20 \%$, and the overall rate of complete improvement after medication use increased from $5 \%$ to $50 \%$. These results suggested that Al-Hijama has a significantly positive therapeutic effect when used either as an adjuvant or as a main treatment for sinusitis.

Previous studies have reported findings related directly or indirectly to the subject of current study. In 2003, Zijlstra et al. ${ }^{[19]}$ investigated the effect of acupuncture on inflammatory diseases. In addition, complementary medicine practitioners frequently used acupuncture when treating patients with chronic sinus and nasal symptoms, as demonstrated in several randomized controlled trials. Furthermore, both acupuncture and dry cupping have been recommended as adjunct therapies for allergic rhinitis ${ }^{[20,21]}$.

Studies, using Al-Hijama for patients with chronic conditions, have reported promising positive effects on the health-related quality of life ${ }^{[22]}$. USA Food and Drug Administration has approved the use of leeches (a type of Al-Hijama) as a means of treatment ${ }^{[23]}$ and Al-Hijama has also been used to treat inflammatory and allergic diseases and in removing the resulting congestion ${ }^{[24]}$. Therefore, Al-Hijama appears to be a potentially useful mode of treatment, as it is an effective, simple, safe, inexpensive, rapid, and socially acceptable method for reducing sinusitis symptoms and related drug use. The current study is distinct from previous studies that discussed Al-Hijama and acupuncture in terms of the effects and roles of similar health problems but did not focus on sinusitis. Regarding limitations, 90\% of selected patients are female so there is a potential of bias. Cupping was used with normal saline nasal drops five times a day with analgesic as needed to give synergetic effect. Acute cases and chronic mixed should be considered for analysis but mainly depending on patient's feedback on questionnaire, which still show that the effect of improvement of symptoms is much better with Al-Hijama. The contribution of this study is emphasized from the significant improvement of symptoms using Al-Hijama based on patient's feedback on questionnaires.

\section{Conclusion}

This study demonstrated the marked superiority of Al-Hijama therapy, which is effective, simple, safe, affordable and not associated with complications, when used correctly, as an adjuvant or alternative treatment for the treatment of sinusitis symptoms. Al-Hijama enhances immune activity and promotes the removal of CPS, and additionally enhances the therapeutic effects of medications. Al-Hijama is expected to benefit every patient; although, the degree of health benefits may range from an improvement to a cure. It is expected that health officials will officially incorporate Al-Hijama into their health care regimens as an adjuvant or alternative treatment for sinusitis patients, as it will reduce the inappropriate use of antibiotics and other medications. Medical staff should be educated about the therapeutic role of Al-Hijama, and Al-Hijama should be practiced by a qualified licensed practitioner (i.e., health official) in hospitals or clinics when indicated or advised. Further investigations are needed to confirm and verify the beneficial effects of Al-Hijama on the therapeutic outcomes of many diseases, including sinusitis.

\section{Acknowledgment}

The authors would like to thank the employees of Sheikh Yousef Abdul Latif Jameel Scientific Chair, Professor Soad Aljaouni, Dr. Eisha Ali, Mrs. Fatma, Mrs. Zakia, and Mrs. Sabria at the Hijama Clinic. In addition, the authors thank all workers at University Medical Service Center, $\mathrm{KAUH}$, and the ENT department. Finally, the authors give great thanks for all the patients, who participated in this study, and-before all-thank Allah for helping and guiding our work in this study.

\section{Ethical Statement}

This study was conducted according to the ethical principles of the Declaration of Helsinki. The Committees of the Faculty of Medicine at KAU, Jeddah, Kingdom of Saudi Arabia approved the initiation of the outpatient cupping clinic at KAUH. The proposal of the current intervention study was approved by Institutional Review Board of $\mathrm{KAUH}$, and the results were displayed periodically. The trial is registered with the National Committee of Biological and Medical Ethics (Number: HA-02-J-008). Consent was obtained 
from each patient after completing an interview at the Prophetic Medicine Clinic. Patients were free to withdraw from the research at any time without any effects to the provision of services.

\section{Funding Sources}

This study was funded by the Sheikh Yousef Abdul Latif Jameel Prophetic Medicine Scientific Chair, KAU, Jeddah, Kingdom of Saudi Arabia (Grant No. $\mathrm{MBK} / 5 / 437)$.

\section{References}

[1] Meltzer EO, Hamilos DL. Rhinosinusitis diagnosis and management for the clinician: a synopsis of recent consensus guidelines. Mayo Clin Proc 2011; 86(5): 427443.

[2] Gliklich RE, Metson R. The health impact of chronic sinusitis in patients seeking otolaryngologic care. Otolaryngol Head Neck Surg 1995; 113(1): 104-109.

[3] Caspersen LA, Walter LM, Walsh SA, Rosenfeld RM, Piccirillo JF. Plain language summary: adult sinusitis (sinus infection). Otolaryngol Head Neck Surg 2015; 153(2): 161-166.

[4] Sarber KM, Dion GR, Weitzel EK, McMains KC. Approaching chronic sinusitis. South Med J 2013; 106(11): 642-648.

[5] Rosenfeld RM, Piccirillo JF, Chandrasekhar SS, Brook I, Ashok Kumar K, Kramper M, Orlandi RR, Palmer JN, Patel ZM, Peters A, Walsh SA, Corrigan MD. Clinical practice guideline (update): adult sinusitis. Otolaryngol Head Neck Surg 2015; 152(2 Suppl): S1-S39.

[6] Dubin M, Lee J, Woodard TD, Wise SK. Endoscopic sinus surgery. Am Rhinol Soc. 2015. Accessed <http://care. american-rhinologic.org/ess>.

[7] Care America. Endoscopic sinus surgery. 2017. Retrieved from <http://care.american-rhinologic.org/ess >

[8] [No author listed.] History of Apitherapy. <http:// Medicineworld.org>. Retrieved 31 August 2016.

[9] British Acupuncture Council. Acupuncture and sinusitis. 2014. Retrieved from: <https://www.acupuncture.org.uk/ a-to-z-of-conditions/a-to-z-of-conditions/sinusitis.html>.

[10] Litvack J. Complications of sinusitis. 2015 Accessed <http:// care.american-rhinologic.org/complications_sinusitis>.

[11] SUNNAH.COM. The English Translation of Sahih Al Bukhari with the Arabic Text. Al-Saadawi Publications, 1996.

[12] Mahmoud HS, Abou-El-Naga M, Omar NA, El-Ghazzawy HA, Fathy YM, Nabo MM, El Sayed SM. Anatomical sites for practicing wet cupping therapy (Al-Hijamah): in light of modern medicine and prophetic medicine. Altern Integr Med 2013; 2(8): 138-168.
[13] Cao H, Li X, Liu J. An updated review of the efficacy of cupping therapy. PloS One 2012; 7(2): e31793.

[14] AlBedah A, Khalil M, Elolemy A, Elsubai I, Khalil A. Hijama (cupping): a review of the evidence. Focus Altern Complementary Ther 2011; 16(1): 12-16.

[15] El Sayed SM, Al-quliti AS, Mahmoud HS, Baghdadi H, Maria RA, Nabo MM, Hefny A. Therapeutic benefits of Al-hijamah: in light of modern medicine and prophetic medicine. Am J Med Biol Res 2014; 2(2): 46-71.

[16] El Sayed SM, Mahmoud HS, Nabo MM. Methods of wet cupping therapy (Al-Hijamah): in light of modern medicine and prophetic medicine. Altern Integr Med 2013; 2: 111.

[17] Ahmadi A, Schwebel DC, Rezaei M. The efficacy of wetcupping in the treatment of tension and migraine headache. Am J Chin Med 2008; 36(1): 37-44.

[18] van Alphen A, Halfens R, Hasman A, Imbos T. Likert or Rasch? Nothing is more applicable than good theory. J Adv Nurs 1994; 20(1): 196-201.

[19] Zijlstra FJ, van den Berg-de Lange I, Huygen FJ, Klein J. Antiinflammatory actions of acupuncture. Mediators Inflamm 2003; 12(2): 59-69.

[20] Pletcher SD, Goldberg AN, Lee J, Acquah J. Use of acupuncture in the treatment of sinus and nasal symptoms: results of a practitioner survey. Am J Rhinol 2006; 20(2): 235-237.

[21] Pfab F, Schalock PC, Napadow V, Athanasiadis Gl, HussMarp J, Ring J. Acupuncture for allergic disease therapythe current state of evidence. Expert Rev Clin Immunol 2014; 10(7): 831-841.

[22] Al Jaouni SK, El-Fiky EA, Mourad SA, Ibrahim NK, Kaki AM, Rohaiem SM, Qari MH, Tabsh LM, Aljawhari AA. The effect of wet cupping on quality of life of adult patients with chronic medical conditions in King Abdulaziz University Hospital. Saudi Med J 2017; 38(1): 53-62.

[23] Isakhanian GS, Arutiunian VM. [Medicinal leeches: their medical use in the therapy clinic]. Ter Arkh 1991; 63(8): 110-112.

[24] Ameen SMM, Salma O, Ali MT. A clinical study of cupping therapy. Int J Ayush Med Res 2016; 1(2): 15-20. 


\title{
مقارنة بين سلامة وفعالية الحجامة والعلاج الطبي التقليدي لإلتهاب الجيوب

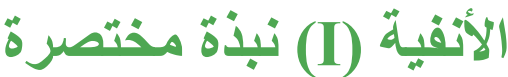

\author{
إيمان عبد العظيم غازي ',"، وسعد محمد المحياويّ ، وسميحة علي مرادّ"، وروان عبد الرحمن الأهدل؛

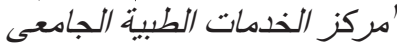

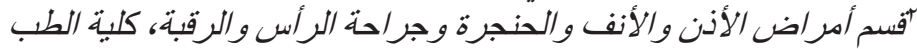

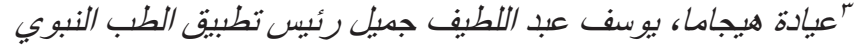

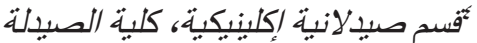 \\ جامعة الملك عبد العزبيز \\ جلة ـ المدلكة العربية السعودية العية
}

المستخلص. تهدف هذه الدر اسة إلى تقييم سلامة وفعالية إستخدام الحجامة (الكاسات) إما كمساعد أو بديل للعلاج الدوائي

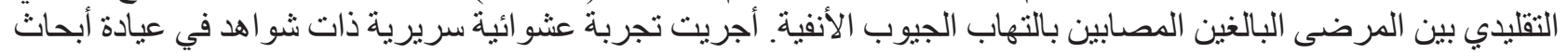

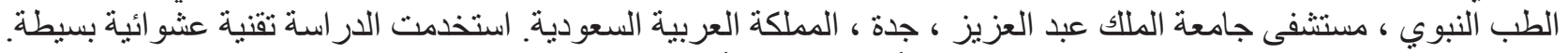

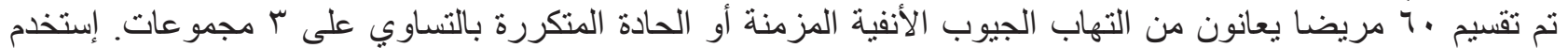

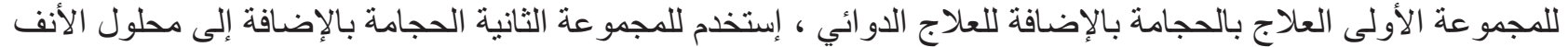

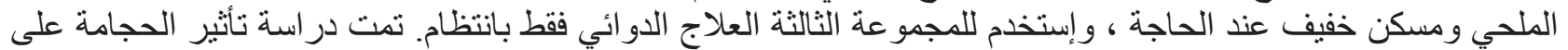

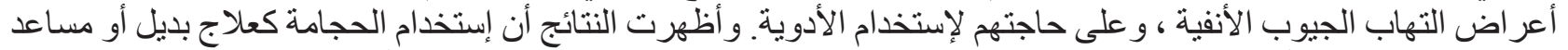

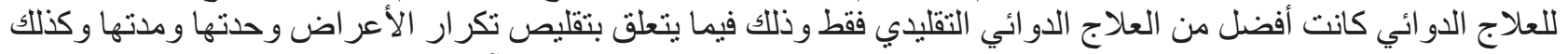

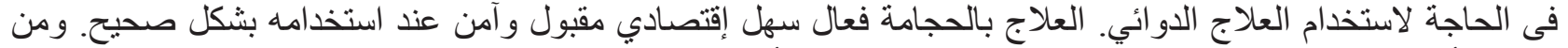
المتوقع أن يستفيد جميع المرضى المصابين بالتهاب الجيوب الأنفية من الحجامة. 